\title{
The effect of exposure to different climatic environments on some blood parameters in young growing pigs
}

J. M. F. Verhagen, M. B. Kreukniet, W. Visser and J. R. van Herwijnen (Department of Animal Husbandry, Wageningen Agricultural University, Marijkeweg 40, 6709 PG Wageningen, Netherlands)

Received 16 December 1986; accepted 2 March 1987

Abstract. Young growing pigs, liveweight $22 \mathrm{~kg}$, were exposed to 4 climatic treatments during 16 days. Treatments were (1) $25^{\circ} \mathrm{C}$, (2) $15^{\circ} \mathrm{C}$, (3) fluctuating temperature over $24 \mathrm{~h}\left(09 \mathrm{~h} 00-19 \mathrm{~h} 0025^{\circ} \mathrm{C}, 21 \mathrm{~h} 00-07 \mathrm{~h} 0015^{\circ} \mathrm{C}\right)$ and (4) fluctuating temperature in combination with draught. In each treatment 20 group-housed pigs were used. Each treatment applied was performed in two replicates. Levels of albumin and globulins before and after exposure were measured in 6 pigs, chosen at random. Leucocytic cells were differentiated. Levels of albumin and globulins were not affected by treatments. Percentage of lymphocytes had decreased and percentage of neutrophils increased after 16 days exposure to fluctuating temperature in combination with draught

Key words: pigs, blood parameters, climatic environment.

Introduction. Climatic environment is known to interfere with resistance and susceptibility of animals to disease (Borysenko \& Borysenko, 1982; Dantzer \& Mormède, 1983; Kelley, 1985). An adverse climatic environment will increase levels of hormones, such as ACTH and corticosteroids, and these may have an indirect or direct effect on the immune system (Blatchford et al., 1978; Dantzer \& Mormède, 1983; Siegel, 1985). These effects on the immune system are important since they are associated with animal health (Kelley, 1985).

Kelley (1983) found an increase in number of lymphocytes and a decline in number of neutrophils after acute cold stress. With chronic cold stress both lymphocytes and neutrophil numbers decreased. Widowski et al. (1984) observed a change in the ratio of neutrophils to lymphocytes in pig's blood after oral administration of cortisol. Administration of ACTH to pigs did not influence number of lymphocytes nor neutrophils (Blecha, 1984). In this study experiments were conducted to investigate the effects after 16 days' exposure to different climatic environments on relative numbers of leucocytes and levels of albumin and globulins in peripheral blood of young growing pigs.

Material and methods. Four climatic treatments were applied, with two replicates per treatment. Treatments of climatic environment consisted of ambient temperatures of $25^{\circ} \mathrm{C}$ and $15^{\circ} \mathrm{C}$, fluctuation in temperature $\left(25^{\circ} \mathrm{C}\right.$ from $09 \mathrm{~h} 00$ to $19 \mathrm{~h} 00$ 
and $15{ }^{\circ} \mathrm{C}$ from $21 \mathrm{~h} 00$ to $07 \mathrm{~h} 00$ ) and a similar rhythm with a superimposed treatment of draught. The draught consisted of an air stream with increased air velocity $(0.8 \mathrm{~m} / \mathrm{s})$ with a temperature $5 \mathrm{~K}$ lower than ambient temperature. Draught was applied periodically at night time during 2 -hour periods $(21 \mathrm{~h} 00-23 \mathrm{~h} 00,01 \mathrm{~h} 00-03 \mathrm{~h} 00$ and $05 \mathrm{~h} 00-07 \mathrm{~h} 00$ ). In the other parts of the night, conditions were as in the other treatments and air velocity was below $0.2 \mathrm{~m} / \mathrm{s}$. During the 2-hour draught periods the draught occurred in an alternating sequence of 4 minutes on and off. Ambient temperature of $25{ }^{\circ} \mathrm{C}$ is within thermal neutrality whereas $15^{\circ} \mathrm{C}$ is below the lower critical temperature for pigs of this age (Bruce \& Clark, 1979). Each climatic treatment lasted for 16 days.

In each experiment 20 pigs, housed in two groups of 10 pigs, were exposed to a climatic treatment. Liveweight of pigs at the initiation of the different treatments was $21.7 \mathrm{~kg}( \pm 2.1 \mathrm{~kg})$ and was not significantly different between treatments and replicates.

At day 0 of each treatment six pigs were randomly chosen and blood samples were taken from the vena brachiocephalica. The same pigs were resampled at day 16 after initial exposure to the climatic treatment. Heparinized blood was used to make blood smears and stained cells (Giemsa) were differentiated according to Juncqueira \& Carneiro (1980). A total number of 200 cells was counted and differentiated into neutrophils, lymphocytes, monocytes, eosinophils and basophils, and they were expressed as a percentage.

The amount of albumin and $\alpha$-, $\beta$ - and $\gamma$-globulin in the serum was determined by electrophoresis (IBL, West-Germany). Analysis of variance was carried out in replicate and climatic treatment as factors (SAS, 1985). Tukey's HSD test was used for multiple range comparison of treatments.

Results. At day 0 values of traits were similar, apart from $\%$ monocytes which was slightly different between groups $(p<0.05)$. Analysis of variance of the blood parameters at day 16 after initial exposure is given in Table 1. Data show that \% lymphocytes and $\%$ neutrophils were significantly affected by climatic treatment. Exposure to fluctuation in ambient temperature combined with a superimposed draught resulted in a significant lower $\%$ of lymphocytes and higher $\%$ of neutrophils compared with $25^{\circ} \mathrm{C}$. The amount of $\alpha$-, $\beta$ - or $\gamma$-globulin was not significantly affected by climatic treatment.

Discussion. Dantzer and Mormède (1983) showed that thermal stress of cattle was elicited by changes in cortisol levels as a result from pituitary-adrenal responses. Low temperature resulted in increased cortisol level which reflected the reaction to the physical quality of the environmental temperature (Dantzer \& Mormède, 1983). This was found also by Blatchford et al. (1978), Hacker et al. (1973) and Bate \& Hacker (1985) for pigs. The effects of steroid hormones or stress on lymphatic tissue lies in the cardinal role played by this tissue in the immune response (Siegel, 1985). The direct effects of corticosteroids, or the indirect effects of ACTH or stress include reductions in lymphatic tissue mass (i.e., thymus, spleen, bursa of Fabricius), a depression in the number of circulating lymphocytes and an increase 


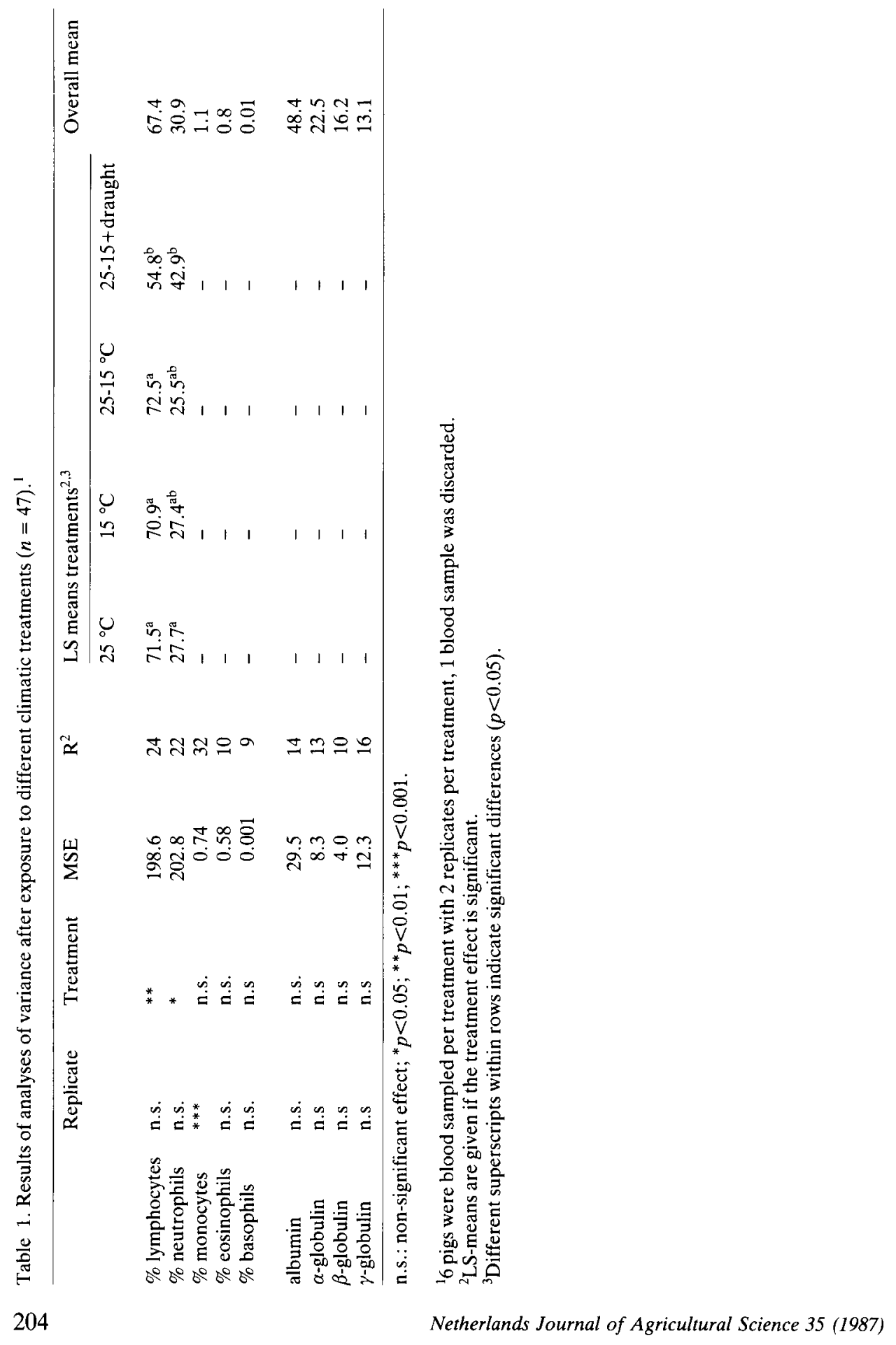


in neutrophilic or heterophilic granulocytes in chickens (Siegel, 1985). Gross \& Siegel (1983) stated that the ratio between both blood parameters could be useful as indicator of stress imposed on animals. Results obtained in this study support the theory of this mechanism since it was found that pigs exposed to a diurnal rhythm in ambient temperature with a superimposed draught treatment also had a lower \% lymphocytes and a higher \% neutrophils. Ambient temperatures within thermoneutrality $\left(25^{\circ} \mathrm{C}\right)$ or below the lower critical temperature $\left(15^{\circ} \mathrm{C}\right)$ and 24 -hour fluctuation in ambient temperature did not cause a change in blood cell ratios at day 16. Adaptation to other treatments than draught may have been completed during this time. Dantzer \& Mormède (1983) and Kelley (1985) stated that changes in the immune system depended on the physical quality of the stimulus. According to Kelley (1985) immune responses might be subjected to adaptive processes. This might account for the differences observed after acute or chronic cold stress, as were found by Kelley (1983). Kelley et al. (1984) found that the cell-mediated response of young calves was modulated by duration of exposure to adverse climatic conditions. It may be assumed that the magnitude of the effect of the applied climatic treatments in these experiments depend on the deviation from the optimal environment (i.e. thermoneutrality) and the combined effect of the duration of the climatic stress. It is therefore important to estimate this deviation and the mechanisms involved in adaptation of animals to adverse climatic factors. State of acclimation will thus interfere with endocrinological status and thus immunological parameters.

Acknowledgements. The authors acknowledge Mr Th. Wensing from the Veterinary Faculty, Clinic for Large Animal Medicine, State University Utrecht for assistance. Mrs G. de Vries is thanked for her cooperation.

\section{References}

Bate, L. R. \& R. Hacker, 1985. Effect of variation and environmental temperature on the concentration of serum cortisol in pregnant sows. Canadian Journal of Animal Science 65: 399-404.

Blatchford, D., M. Holzbauer, D. L. Ingram \& D. F. Sharmann, 1978. Responses of the pituitary-adrenal system of the pig to environmental changes and drugs. British Journal of Pharmacology 62: 244254.

Blecha, F., 1984. Neonatal pigs reared artificially have suppressed in vivo and in vitro cellular immune response. Journal of Animal Science 59: (Suppl. 1): 190.

Borysenko, M. \& J. Borysenko, 1982. Stress behavior and Immunity: Animal models and mediating mechanisms. General Hospital Psychiatry 4: 59-67.

Bruce, J. M. \& J. J. Clark, 1979. Models of heat production and critical temperature for growing pigs. Animal Production 28: 353-369.

Dantzer, R. \& P. Mormède. 1983. Stress in farm animals: a need for reevaluation, Journal of Animal Science 57: 6-18.

Gross, W. B. \& H. S. Siegel. 1983. Evaluation of the heterophil/lymphocyte ratio as a measure of stress in chickens. Avian Diseases 27: 972-979.

Hacker, R. R., M. P. Stefanovics \& T. R. Batra, 1973. Effects of cold exposure on growing pigs: growth, body composition and 17-ketosteroids, Journal of Animal Science, 37: 739-744.

Juncqueira, L. C. \& J. Carneiro, 1980. Basic Histology, Lange Medical Publications, Los Altos, California. 


\section{J. M. F. VERHAGEN, M. B. KREUKNIET, W. VISSER AND J. R. VAN HERWIJNEN}

Kelley, K. W., 1983. Immunobiology of domestic animals as affected by hot and cold weather. Trans American Society of Agricultural Engineers.

Kelley, K. W., R. E. Greenfield, M. T. O'Connor \& C. T. Gaskins, 1984. Acute cold stress in zeranolimplanted steers. Journal of Animal Science 53: (Suppl. 1): 184.

Kelley, K. W., 1985. Immunological consequences of changing environmental stimuli. In: Animal stress, p. 193-223. American Physiological Society.

SAS, 1985. Statistical Analysis System. SAS Institute Inc., Cary, NC, USA.

Siegel, H. S., 1985. Immunological responses as indicators of stress. WPSA Journal 41: 36-45.

Widowski, T., S. E. Curtis \& J. M. McFarlane, 1984. Neutrophil/lymfocyte ratio in pigs fed cortisol. ASAS Midwestern Section, March, 1984, Chicago.

This synopsis is based on a $M$. Sc. thesis entitled 'De invloed van klimaatsfactoren en Haemophilus pleuropneumoniae of the systemische en locale afweer van de jonge mestbig' by M. B. Kreukniet and W. Visser, Department of Animal Husbandry, Wageningen Agricultural University, 1986. vi + 94 pp., 18 figs., 24 tables, 57 refs., 12 appendices. Dutch.

Available as paper copy (order R072P, $f 20$ including postage) or microfiche (order R072M, f 12.50 including postage) at: NARD, clo Pudoc, P.O. Box 4, 6700 AA Wageningen, Netherlands (telex 45015 blhwg). 